Mikele Macho-Aizpurua'

Itziar Angulo-López'

Jesus-María Arciniega-

Garcia $^{2}$

José-Luis Díaz-de-Tuesta

del-Arco'

\section{Bacteriemia de origen urinario por Lactobacillus delbrueckii ssp. sunkii}

\author{
Osakidetza, Hospital Universitario Basurto, Servicio de Microbiología Clínica y Control de Infección. Avenida \\ Montevideo 18, 48013 Bilbao, España. \\ ${ }^{2}$ Osakidetza, Hospital Universitario Basurto, Servicio de Urología. Avenida Montevideo 18, 48013 Bilbao, España.
}

Article history

Received: 5 February 2021; Revision Requested: 7 March 2021; Revision Received: 7 March 2021; Accepted: 1 April 2021; Published: 3 June 2021

\section{Sr. Editor:}

Los microorganismos del género Lactobacillus son comensales de las mucosas orofaringea, digestiva y genitourinaria femenina [1]. Presentan escasa o nula virulencia en personas inmunocompetentes y podrian actuar inhibiendo el crecimiento de microorganismos patógenos en el tracto gastrointestinal y genitourinario al producir ácido láctico por fermentación de la glucosa. La prevalencia de las infecciones causadas por estos microorganismos está subestimada porque su aislamiento suele considerarse una contaminación; incluso, el valor clínico del aislamiento de lactobacilos en muestras estériles es objeto de debate; aunque, cada vez, se describe con mayor frecuencia su implicación en infecciones, especialmente en pacientes inmunodeprimidos [1].

Aunque la infección del tracto urinario (ITU) por Lactobacillus delbrueckii es una entidad descrita cada vez con mayor frecuencia [2-6], el caso que presentamos de bacteriemia por $L$. delbrueckii ssp. sunkii de origen urinario, es muy poco común: mujer de 92 años, con antecedentes de dislipemia, hipotiroidismo y leucopenia autoinmune, diverticulosis colónica y enfermedad de Parkinson. Acude a Urgencias por fiebre, vómitos y malestar general. En la exploración física la paciente estaba desorientada, somnolienta y con dolor en fosa ilíaca izquierda. Presentaba fiebre de $38^{\prime} 4^{\circ} \mathrm{C}$ y taquicardia de $124 \mathrm{lpm}$. En la analítica destacaban urea de $85 \mathrm{mg} / \mathrm{dL}$, creatinina de 1,50 mg/ $\mathrm{dL}, 4.220 / \mu \mathrm{L}$ leucocitos con $85,3 \%$ de neutrófilos y proteína $\mathrm{C}$ reactiva de $227,8 \mathrm{mg} / \mathrm{L}$. El análisis sistemático de orina mostraba parámetros dentro de la normalidad. En la citometria de flujo (UF-1000i® Sysmex) se observaban 51 leucocitos/ $\mu \mathrm{L}, 8.156$ bacterias $/ \mu \mathrm{L}, 20$ hematies/ $\mu \mathrm{L}$ y 55 células epiteliales/ $\mu \mathrm{L}$; y en la TAC abdomino-pélvica urolitiasis obstructiva izquierda. Se ad-

Correspondencia:

Mikele Macho-Aizpurua

Hospital Universitario Basurto, Servicio de Microbiologia Clinica y Control de Infección. Avenida Montevideo 18, 48013 Bilbao, España.

Teléfono: 665929262

E-mail:mkl_iei@hotmail.com ministró piperacilina-tazobactam previa extracción de cultivos y se realizó una derivación urinaria. En el urocultivo, tras 24 horas de incubación a $37^{\circ} \mathrm{C}$, se observaron $>100.000 \mathrm{UFC} / \mathrm{mL}$ de pequeñas colonias azules en cultivo puro en el medio cromogénico BD Chromagar Orientation Medium. Por espectrometría de masas (Maldi-Tof ${ }^{\circledR}$, Bruker Daltonics, GmbH) se identificó L. delbrueckii ssp. sunkii (score de 2.06). Simultáneamente, a las 27 horas de incubación se obtuvo crecimiento en el frasco anaerobio de hemocultivo BD (BACTEC ${ }^{\mathrm{TM}}$ Lytic/10 Anaerobic/F flask (BD Diagnostics, Sparks, MD). La tinción de Gram mostraba bacilos grampositivos no esporulados; y en los subcultivos en agar sangre Brucella (BD Brucella 5\% SB) y en chocolate (GC choco $\mathrm{BD}$ ), incubados a $37^{\circ} \mathrm{C}$ en atmósfera anaerobia y en atmósfera aerobia con $5 \%$ de $\mathrm{CO}_{2}$ respectivamente, aparecian colonias alfa-hemolíticas y catalasa negativas. La identificación coincidió con la del urocultivo (score de 2.41). Siguiendo las recomendaciones establecidas por EUCAST para anaerobios grampositivos, se realizó la lectura del antibiograma mediante tiras de gradiente en agar Mueller-Hinton sangre desfibrinada (Mueller Hinton BD) tras 24 horas de incubación a $37^{\circ} \mathrm{C}$ y $5 \%$ de $\mathrm{CO}_{2}$. La cepa fue sensible a ampicilina $(\mathrm{CMl}=0,25 \mathrm{mg} / \mathrm{L})$, amoxicilina-clavulánico (CMI=0,125 mg/L), piperacilina-tazobactam $(\mathrm{CMl}=0,38 \mathrm{mg} / \mathrm{L})$, imipenem $(\mathrm{CMl}=0,047 \mathrm{mg} / \mathrm{L})$, clindamicina $(\mathrm{CMl}=0,047 \mathrm{mg} / \mathrm{L})$ y vancomicina $(\mathrm{CMI}=0,25 \mathrm{mg} / \mathrm{L})$ y resistente a metronidazol (CMI >256 mg/L). La paciente evolucionó favorablemente tras 11 dias de antibioterapia y se procedió al alta hospitalaria al cabo de 33 dias de ingreso por motivos sociales.

Las infecciones asociadas al género Lactobacillus incluyen bacteriemia, endocarditis, ITU y otras infecciones localizadas [1]. La bacteriemia y la endocarditis afectan principalmente a inmunodeprimidos tras manipulaciones orodentales y procedimientos endoscópicos en pacientes con fístulas o neoplasias intestinales o ginecológicas [6]. La ITU suele pasar desapercibida tras el análisis bioquímico de orina, al tratarse de bacterias que no reducen los nitratos. Sin embargo, el crecimiento puro y significativo de lactobacilos en urocultivo debe considerarse, máxime si se acompaña de bacteriemia. La mayoría de lactoba- 
cilemias de origen urinario se presentan en mujeres de 60 a 70 años. Entre los factores de riesgo de infección por este microorganismo se incluyen: la urolitiasis; la inmunosupresión secundaria a diabetes o cáncer, y el uso previo de antibióticos [2-5] ya que favorece la selección de microorganismos resistentes. Otro factor que podria favorecer la lactobacilemia es el consumo de probióticos [7]. La mortalidad atribuible a la bacteriemia por lactobacilos es baja. En el trabajo de Husni et al. la bacteriemia se resolvió en el 98\% de los pacientes [8]. En otras series la mortalidad al año alcanza el 48\%, atribuible en gran medida a las enfermedades de base de los pacientes [7]. Por tanto, aunque estos microorganismos raramente son patógenos, pueden ser marcadores de enfermedad severa y rápidamente fatal [4]. Respecto al tratamiento, aunque no existe consenso, la lactobacilemia puede tratarse con betalactámicos como ampicilina, asociando aminoglucósidos en endocarditis [9].

En este caso, la paciente presentaba urolitiasis y estasis urinaria; no se observaba un uso previo de antibióticos ni probióticos; pero, al igual que lo descrito en otros casos [3-6], presentaba hipotiroidismo. L. delbrueckii presenta una resistencia uniforme a cotrimoxazol, fosfomicina, ciprofloxacino y muy extendida a vancomicina y metronidazol [4]. La cepa aislada en nuestra paciente fue sensible a vancomicina, caracteristica común de especies del grupo Lactobacillus acidophilus [10]; y la evolución clínica fue favorable con piperacilina/tazobactam.

\section{FINANCIACIÓN}

Los autores declaran no haber recibido financiación para la realización de este estudio.

\section{CONFLICTO DE INTERESES}

Los autores declaran no tener ningún conflicto de intereses.

\section{BIBLIOGRAFÍA}

1. Slover C, Danziger L. Lactobacillus: a Review. Clin Microbiol Newsl. 2008;30(4):23-27. doi: 10.1016/j.clinmicnews.2008.01.006.

2. Bernier M, Njomnang Soh $P$, Lochet $A$, Prots $L$, Félice $R$, Senescau A et al. Lactobacillus delbrueckii: probable agent of urinary tract infections in very old women. Pathol Biol (Paris). 2012;60(2): 140-2. doi: 10.1016/j.patbio.2010.04.003.

3. Darbro BW, Petroelje BK, Doern GV. Lactobacillus delbrueckii as the cause of urinary tract infection. J Clin Microbiol. 2009;47(1):275-7. doi: 10.1128/JCM.01630-08.

4. Duprey KM, McCrea L, Rabinowitch BL, Azad KN. Pyelonephritis and Bacteremia from Lactobacillus delbrueckii. Case Rep Infect Dis. 2012;2012:745743. doi: 10.1155/2012/745743.

5. Jiménez-Guerra G, Pérez-Ramírez MD, Navarro-Mari JM, Gutiérrez-Fernández J. Infección del tracto urinario por Lactobacillus delbrueckii, microorganismo usado como probiótico. Rev Esp Quimioter. 2017;30(3):229-230.
6. Jover-García J, Colomina-Rodriguez J. Infección urinaria por Lactobacillus delbrueckii. Caso 658. [cited 15 November 2020]. Available from: http://www.wider.es/casosclinicos/.

7. Salminen MK, Rautelin H, Tynkkynen S, Poussa T, Saxelin M, Valtonen, Ville $V$ et al. Lactobacillus bacteremia, clinical significance, and patient outcome, with special focus on probiotic L. rhamnosus GG. Clin Infect Dis. 2004;38(1):62-9. doi: 10.1086/380455.

8. Husni RN, Gordon SM, Washington JA, Longworth DL. Lactobacillus bacteremia and endocarditis: review of 45 cases. Clin Infect Dis. 1997;25(5):1048-1055. doi: 10.1086/516109.

9. Cannon, JP, Lee TA, Bolanos JT, Danziger LH. Pathogenic relevance of Lactobacillus: a retrospective review of over 200 cases. Eur J Clin Microbiol Infect Dis. 2005;24(1): 31-40. doi: 10.1007/s10096-0041253-y.

10. Klare I, Konstabel C, Werner G, Huys G, Vankerckhoven V, Kahlmeter $\mathrm{G}$ et al. Antimicrobial susceptibilities of Lactobacillus, Pediococcus and Lactococcus human isolates and cultures intended for probiotic or nutritional use. J Antimicrob Chemother. 2007;59(5):900912. doi: $10.1093 / \mathrm{jac} / \mathrm{dkm} 035$. 